\title{
El Estado capitalista en América Latina, ¿potencial factor de cambio o mero instrumento de dominación?
}

\author{
The capitalist State in Latin America, potential change factor or mere \\ instrument of domination?
}

\author{
Víctor Damián Medina*
}

\begin{abstract}
Resumen: Partiendo de reflexiones de Aricó, este artículo problematiza la concepción del Estado en Marx y su posible incidencia en el modo en que fue analizada la experiencia política latinoamericana. Señala la existencia de elementos conceptuales que el propio Marx ofrece para comprender las funciones del Estado capitalista en la Europa occidental y cómo pueden ser analizados en la formación de las naciones latinoamericanas. En este orden, se resalta su acción cohesiva y de relativa autonomía respecto a la clase dominante como aspectos que, además, permiten repensar la vía democrática al socialismo.
\end{abstract}

Palabras clave: Estado; capitalismo; Latinoamérica; Democracia; Socialismo

\begin{abstract}
Starting from Aricó's reflections, this paper discuss Marx's concept of State and its possible impact on the way the Latin American political experience was analyzed. The paper indicates the existence of conceptual elements that Marx himself offers to understand the functions of the capitalist State in Western Europe and how it can be analyzed in the formation of Latin American nations. In this order, the cohesive action of the state and its relative autonomy from the ruling class is highlighted as aspects that also allow rethink the democratic way to socialism.
\end{abstract}

Keywords: State; Capitalism; Latin America; Democracy; Socialism

Recibido: 17 mayo 2016

Aceptado: 22 octubre 2016

\footnotetext{
* Argentino. Licenciado en Sociología (Universidad de Buenos Aires). Magister en Ciencias Sociales con mención en política y gestión pública (Universidad Nacional de Quilmes). Doctorando en la Universidad de Buenos Aires. Investigador adjunto en Fundación Bariloche. damianviktor@yahoo.com.ar
} 


\section{Introducción}

Al referir las circunstancias que mediaron en la asimilación del marxismo en América Latina, José María Aricó enumera una serie de hechos históricos que condicionaron su expresión en la cultura política de la región. En particular, se detiene en el supuesto escaso apego y dedicación analítica que Marx le confirió a Latinoamérica. Y no sólo Marx, Aricó también señala que, en general, desde el marxismo como corpus teórico-político se ejerció un "soslayamiento prejuicioso" que atentó contra todo abordaje que propusiera un estudio sistemático y diferenciado de su historia. ${ }^{1}$ En este sentido, la experiencia política latinoamericana quedó huérfana de esfuerzos analíticos similares a los que en el viejo mundo sendos marxistas habían iniciado para conceptualizar las situaciones políticas de las distintas realidades europeas. No se replicaron de igual forma los programas doctrinarios y las tareas políticas que un abordaje analítico diferenciado, propio de la situación local, ameritaba (entre otras razones, porque Latinoamérica no ofrecía como en Europa la existencia de una clase obrera consolidada y organizada políticamente). ${ }^{2}$

Pero, a fin de explicar y analizar este soslayo, lo más interesante de la argumentación de Aricó es cuando identifica como parte del problema la concepción teórica de Marx acerca del Estado moderno. En efecto, señala que en su afán de oponerse a la definición hegeliana de Estado, orientada a asignarle a éste un rol más protagónico y fundante de "eticidad" en la sociedad civil, el padre del socialismo científico descartó todo posible rol que lo situara como un agente con capacidades reales de autonomía. ${ }^{3}$ La postura de Marx respecto al Estado moderno -orientado en definitiva a satisfacer determinados intereses de clase- terminaría derivando en un corsé teórico para pensar la historia de América Latina y el papel preponderante que tuvieron los Estados en la modelación de sus naciones.

\footnotetext{
${ }^{1}$ José María Aricó, "Marx y América Latina", en Nueva Sociedad Nro. 66, Buenos Aires mayo-junio 1983, 47-58.

${ }^{2}$ En este aspecto Aricó se encarga de aclarar que Marx buscó evitar la caída reduccionista en muchos de sus análisis "no europeos" (como los dedicados a Rusia, por ejemplo) tratando de disolver las ortodoxias y esquematismos que una visión eurocéntrica pudiera suponerle. Más bien, los obstáculos que observa los encuentra en cierta tradición marxista canonizada, y particularmente la seguida por el marxismo latinoamericano, que salvo el caso de Mariátegui, obvió la singularidad del contexto latinoamericano interpretando la región desde elementos analíticos ideados para pensar la experiencia social y política europea.

${ }^{3} \mathrm{Al}$ respecto, Harvey señala que, de acuerdo con Hegel, el Estado moderno tenía la capacidad de mediar entre dos ámbitos de la vida social cuya eticidad era contrapuesta: la familia, representada por el altruismo personal de sus miembros y la sociedad civil, esfera del egoísmo y sobretodo, "esfera de la competencia de mercado, la división social del trabajo y la 'interdependencia universal' tal y como se describe en la economía política". En tales términos, añade: "La evidente tensión entre la familia y la sociedad civil -entre las esferas pública y privada de la vida social- sólo puede resolverse, en opinión de Hegel, mediante la adquisición de una conciencia universalista por parte de todos y la expresión objetiva de dicha tendencia mediante las instituciones del Estado moderno" (David Harvey, Espacios del capital: Hacia una geografía crítica, Madrid, Akal Ediciones S.A., 2011, 304).
} 
Ahora bien, teniendo en cuenta que es señalada como una de las causas de su incomprensión y objeto de reclamo analítico hacia los procesos que estaban en curso en América Latina, ¿puede esta concepción teórica ajustarse enteramente a Marx? Al margen de las consideraciones de Aricó sobre las motivaciones que habrían terciado en su actitud que solo sirven en este caso como introducción al problema-, y que habrían incidido en la recepción regional de su obra, ¿qué elementos ofrece el propio Marx para pensar en un rol más autónomo del Estado y cómo pueden ser utilizados para pensar la formación de las sociedades nacionales en Latinoamérica? Finalmente, en función de sintonizar y orientar una respuesta a estos interrogantes, ¿qué otras definiciones acerca del Estado capitalista pueden ser rescatadas desde el marxismo para abordar esta experiencia política? Y además, ¿cómo pueden estas otras definiciones contribuir a pensar los cambios políticos y sociales, en general, y en Latinoamérica, en particular?

Con el objetivo de abordar estos interrogantes en las siguientes secciones se expondrán los vínculos establecidos entre el Estado y las sociedades nacionales como factores concurrentes a la constitución de los mercados y la consolidación del modo de producción capitalista. Se tomará el ejemplo latinoamericano para comprender como algunas de las funciones estatales identificadas por Marx en el occidente europeo se alejan de las definiciones instrumentalistas y encuadran en la experiencia política regional. Y cómo también desde perspectivas que señalan la capacidad de autonomía del Estado pueden ser repensados los cambios sociales $\mathrm{y}$, en particular, la vía democrática al socialismo propuesta por Poulantzas y García Linera.

\section{El Estado nacional y el desarrollo del capitalismo}

Aricó hace bien en observar que en la formación y consolidación de las naciones latinoamericanas el accionar estatal tuvo una participación más activa y decidida que lo que pudiera indicar una definición del Estado como la que le adjudica a Carlos Marx ${ }^{4}$. Pero también es necesario señalar que esta participación estatal se inscribió en un proceso de afianzamiento hegemónico del capitalismo que se construyó a la par del nacimiento de las naciones latinoamericanas.

Siguiendo a Zavaleta Mercado ${ }^{5}$, estos procesos nacionales estuvieron inexorablemente unidos a la consolidación de las relaciones de producción capitalistas, que en un comienzo eran inexistentes o bien convivían de manera precaria con otras relaciones de producción. Al respecto, el citado autor señala:

Es metafísico suponer que ya hay una "vida económica común" antes del capitalismo, o sea, antes del mercado o, si se quiere ser preciso, antes de que se instale la forma dinero del valor. Por la opuesta, en rigor, la construcción de la nación no concluye ni siquiera cuando se ha unificado

\footnotetext{
${ }^{4}$ Ibid, 48-49.

${ }^{5}$ René Zavaleta Mercado, Clases sociales y conocimiento, La Paz, Editorial Los Amigos del Libro, 1988.
} 
la clase dominante o las fracciones que la componen, sino cuando se han unificado los modos de producción en uno solo. Por eso es legítimo decir que ni siquiera la mera circulación capitalista garantiza la verdadera existencia de la nación. ${ }^{6}$

Dicho esto, cabe preguntarse si acaso Marx consideró estas funciones estatales y por tanto un protagonismo del Estado que lejos podrían ubicarlo en una definición que impidiera su funcionalidad teórica desde la experiencia política y la historia de América Latina. Y, por el contrario, pueda identificarse en él una concepción del Estado que encuadre en un grado de participación y compromiso mayor que el que Aricó le adosa refiriendo la singularidad de la experiencia latinoamericana. Esto puede entenderse mejor si, acordando con Zavaleta Mercado, se concede que la consolidación de "La Nación", o las naciones, como fin o ideal supremo que persigue el Estado moderno supone de manera conjunta la realización de políticas tendientes a sellar el dominio de las relaciones sociales de producción capitalista. Esto es, asumiendo un rol activo en la constitución de las condiciones de producción y favoreciendo mediante su intervención los intereses de la burguesía como clase dominante.

Bajo este marco, no pueden entenderse de otro modo el largo trajinar que supusieron las guerras de la independencia en no pocas regiones latinoamericanas. Pero también, luego de establecida la independencia, en las divisiones territoriales creadas por los colonizadores europeos -como las provincias unidas del Río de la Plata- debe destacarse la sucesión de guerras civiles y otras pujas por el dominio de las fronteras y las nuevas tierras pasibles de ser incorporadas a la producción. En estos conflictos, que incluyeron despojos y diversos actos de rapiñería con el objeto de separar a los productores de sus medios de producción y crear masas de asalariados disponibles para el capital, no fue menor la participación de los Estados recientemente formados. En efecto, la consolidación de las naciones latinoamericanas implicó el esfuerzo estatal, coercitivo y de identificación cultural con la idea de nación, tendiente a imponer estas condiciones de producción, lo cual supuso un proceso de articulación no carente de complejidad:

Definido el Estado como instancia de articulación de relaciones sociales, es difícil pensar en relaciones más necesitadas de articulación y garantía de reproducción que las implicadas en una economía de mercado plenamente desarrollada, es decir, en un sistema de producción capitalista. La existencia del Estado presupone entonces la presencia de condiciones materiales que posibiliten la expansión e integración del espacio económico (mercado) y la movilización de agentes sociales en el sentido de instituir relaciones de producción e intercambio crecientemente complejas mediante el control y empleo de recursos de dominación. Esto significa que la formación de una economía capitalista y de un Estado nacional son aspectos de un proceso único, aunque

${ }^{6}$ Zavaleta Mercado, op. cit., 2. 
cronológica y espacialmente desigual. Pero además implica que esa economía en formación va definiendo un ámbito territorial, diferenciando estructuras productivas y homogeneizando intereses de clase que, en tanto fundamento material de la nación, contribuyen a otorgar al Estado un carácter nacional. ${ }^{7}$

Y en Marx puede sugestivamente reconocerse la importancia de este proceso y el rol del Estado en el devenir del capitalismo, aunque no necesariamente hiciera alusión al caso latinoamericano. ${ }^{8}$ En primera instancia, y de forma explícita, lo hace en el capítulo XXIV del tomo 1 de "El Capital", al describir y analizar los factores que, sedimentados en un extenso periodo de tiempo, derivaron en la llamada acumulación originaria del capital en la Europa occidental. Pero también lo retoma en el último capítulo de dicho tomo, el XXV, cuando analiza los intentos de sobrellevar emprendimientos capitalistas en regiones que no ofrecían las condiciones de producción para ello.

En el occidente de Europa, patria de la economía política, el proceso de la acumulación originaria se halla ya, sobre poco más o menos, terminado. En estos países el régimen capitalista ha sometido directamente a su imperio toda la producción nacional o, por lo menos, allí donde las cosas no están todavía lo bastante maduras, controla indirectamente las capas sociales con él coexistentes, capas caducas y pertenecientes a un régimen de producción anticuado. (...) En las colonias, la cosa cambia. Aquí el régimen capitalista tropieza por todas partes con el obstáculo del productor que, hallándose en posesión de sus condiciones de trabajo, prefiere enriquecerse él mismo con su trabajo a enriquecer al capitalista. ${ }^{9}$

En ambos casos Marx despoja al capital de toda reificación sustancialista y deja al descubierto que se trata de una relación social que requiere de una serie de condiciones para su reproducción, siendo la más importante de ellas la existencia de asalariados que acepten vender su fuerza de trabajo.

Wakefield descubre en las colonias que no basta que una persona posea dinero, medios de vida, máquinas y otros medios de producción, para que se le pueda considerar capitalista, si le falta el complemento: el obrero asalariado, el otro hombre obligado a venderse voluntariamente...y descubre que el capital no es una cosa, sino una relación social entre personas a las que sirven de vehículo las cosas. ${ }^{10}$

\footnotetext{
${ }^{7}$ Oscar Oszlak, Andrés Fontana, y Leandro Gutiérrez, La formación del Estado argentino, Buenos Aires, Editorial de Belgrano, 2004, 18.

${ }^{8}$ Carlos Marx, El capital: Crítica de la economía política, México, Fondo de cultura económica, 1995.

${ }^{9}$ Marx, op. cit., vol. 1, 650.

${ }^{10}$ Marx, op. cit., vol. 1, 651.
}

列 
Esta aclaración desfetichista no solo permite desmitificar el origen mágico que la economía política le había asignado al capital hasta ese momento, sino que también lo sitúa en la crudeza de su realización: los ultrajes y la desposesión de sus medios de vida a numerosos productores signaron su ascenso y consolidación como relación social "con trazos indelebles de sangre y fuego" ". Pero también en ambos capítulos, y esto sí es lo más importante en el contexto de este trabajo, se señala el rol activo del Estado y las políticas que puede instrumentar para consolidar esta relación, sea en las naciones de la Europa occidental como en las colonias ultramarinas. Al decir de Harvey, la comparación de estas dos situaciones sincera una relación de necesaria exclusión:

La misma verdad, sin embargo, se expresa en las políticas territoriales seguidas en las colonias, como las de Wakefield, donde los poderes de la propiedad privada y el Estado debían usarse para excluir a los trabajadores del acceso fácil a tierra gratuita para conservar una base de trabajadores asalariados para la explotación capitalista. Así la burguesía se vio forzada a reconocer en las colonias lo que intentaba ocultar en su país: que el trabajo asalariado se basa en apartar por la fuerza al trabajador del control sobre los medios de producción. ${ }^{12}$

Tomando en cuenta que para Marx el aparato de policía del Estado cumple un papel fundamental en este proceso, debe entonces cuestionarse el rol puramente instrumental -o apéndice de los intereses de clase, como diría Poulantzas ${ }^{13}$ - que lo mantendrían ajeno a cualquier clase de incidencia sobre la sociedad civil.

Como espacio de reconocimiento entre ciudadanos formalmente iguales que idealmente- compartirían una misma idiosincrasia, la construcción de una nación no puede remitirse meramente a una lógica capitalista de reproducción de las condiciones de producción. Estos actos y tareas las ejerce el Estado con la pretensión de integrar bajo la esfera nacional las diferencias evidentes entre los que poseen los medios de producción y los que solo pueden ofrecer su fuerza de trabajo para reproducirse como asalariados libres. Pero se necesitan actos estatales que sobrepasen estas condiciones materiales de existencia y precipiten en la superestructura la idea de nación bajo otras coordenadas valorativas.

La peor vulgarización es la que supone que el Estado puede existir solo en la superestructura, como si se colgara al revés. Sin una acción extraeconómica, es decir, estatal de algún modo, es poco concebible la destrucción de las barreras que hay entre hombres y hombres, entre partes de un territorio sin embargo continuo (es decir, potencialmente 'nacional'), etcétera. Aquí tenemos un reverso de lo anterior: no la nación

\footnotetext{
${ }^{11}$ Marx, op. cit., vol. 1, 609.

${ }^{12}$ David Harvey, Espacios del capital: Hacia una geografía crítica, Madrid, Akal Ediciones S.A., $2011,318$.

${ }^{13}$ Nicos Poulantzas, Estado, poder y socialismo, México, Siglo Veintiuno Editores, 2005, 151.
} 
como asiento material del Estado nacional sino el Estado como constructor de la nación. ${ }^{14}$

En estos términos, entonces, es que Zavaleta Mercado afirma que el contexto ideal para el desarrollo del capitalismo supone la existencia de un Estado nacional que de forma a un tipo de colectividad en el que puedan desarrollarse las fuerzas productivas de tipo capitalista. $^{15}$

\section{La autonomía relativa del Estado}

Si se asume que el Estado concurre de manera activa en la formación de la colectividad nacional que permite que el capitalismo se consolide como modo de producción hegemónico, debe, por otra parte, señalarse que las tareas nacionales exceden estos propósitos económicos. Al respecto Oszlak, Fontana y Guitérrez señalan:

La constitución de la nación supone -en un plano material- el surgimiento y desarrollo, dentro de un ámbito territorialmente delimitado, de intereses diferenciados generadores de relaciones sociales capitalistas; y en un plano ideal, la creación de símbolos y valores generadores de sentimiento de pertenencia que -para usar la feliz imagen de O' Donnell- tienden un arco de solidaridades por encima de los variados y antagónicos intereses de la sociedad civil enmarcada por la nación. ${ }^{16}$

La magnitud de estos otros propósitos - no inmediatamente ligados a la producción, pero que igualmente contribuyen al mantenimiento de la unidad nacional que la condicionaconfiere al Estado otra magnitud, otro "status", que lo aparta de ser puramente un artefacto, un instrumento, de la clase dominante.

García Linera señala que el Estado representa la monopolización legítima de los recursos de una comunidad. Pero esta apropiación de unos pocos, de los gobernantes, no puede existir "sin socialización o universalización de los procedimientos, saberes, conquistas, derechos, e identidades"17: solo puede hacerse a partir de la comunitarización de esos recursos y de su asiento social en la comunidad de la que el Estado es parte. En la formación de esa comunidad, que comparte un territorio -una lengua, una tradición, etc.fruto de un proceso histórico, interviene el Estado promoviendo y construyendo los recursos y los valores comunes que le dan sustento. En la comunitarización de esos recursos y en la monopolización de lo común descansa la dominación estatal,

\footnotetext{
${ }^{14}$ Zavaleta Mercado, op. cit., 211.

${ }^{15}$ Zavaleta Mercado, op. cit., 211.

${ }^{16}$ Oszlak, op. cit., 19.

17 Álvaro García Linera, "Estado, democracia y socialismo", Universidad de la Sorbona de París, Coloquio Internacional dedicado a la obra de Nicos Poulantzas: un marxismo para el siglo XXI, 2015, 5.
} 
contribuyendo a producir lo común, pero apropiándose a su vez de recursos que pertenecen a toda la sociedad.

El Estado solo puede producirse en la historia contemporánea si produce (como fruto de las luchas y de las relaciones sociales) bienes comunes, recursos pertenecientes a toda la sociedad, como la legalidad, la educación, la protección, la historia cívica, los aportes económicos para el cuidado de los demás, etc.; pero este común únicamente puede realizarse si al mismo tiempo de producirse, también se inicia el proceso de su monopolización, su concentración y su administración por unos pocos que, al realizar esa monopolización, consagran la existencia misma de los bienes comunes. ${ }^{18}$

En este sentido, la clave de esta dominación consiste en hacer creer, en convencer a la comunidad que participa en su producción, que la apropiación monopólica de esos recursos la favorece. Este convencimiento ideológico es el que el Estado busca lograr en el colectivo nacional para legitimar su dominio político y, a su vez, legitimar el uso de la violencia física que eventualmente pudiera ejercer. Es lo que posibilita, en definitiva, el sostenimiento de un orden social concreto, territorial y económicamente delimitado, y el desarrollo hegemónico del capitalismo por sobre otros modos de producción. La identidad nacional y la base territorial de esa identidad colectiva es la que permite la extensión del vínculo social y, particularmente, las relaciones de producción que permiten el desarrollo de las fuerzas productivas. Así, el Estado moderno capitalista, lejos de ser una cosa, un instrumento que es utilizado mecánicamente por las clases dominantes para su propio beneficio, es una unidad política que representando a un conjunto de relaciones sociales organiza las contradicciones de las distintas fuerzas en pugna.

Pero esto no quiere decir que no se procure la hegemonía de la clase dominante; al contrario, el convencimiento ideológico supone especialmente afirmar los intereses generales de la burguesía. Sin embargo, esto no obstaculiza que este objetivo se logre bajo la organización de un equilibrio inestable entre las fracciones de clase burguesas, y dentro de estas las que se han vuelto hegemónicas, y las clases dominadas. ${ }^{19}$ La cesión de determinadas prerrogativas que pudieran beneficiar a éstas últimas forman parte de las tensiones generales de este equilibrio, pero también de las acciones de relativa autonomía que puede ejercer el Estado en relación a los intereses más inmediatos y particulares de las clases dominantes.

En estos términos, entonces, es que el Estado capitalista puede ser concebido como relación: en él se condensa y materializa la relación de fuerzas entre las distintas fracciones de clase. ${ }^{20}$ Considerando este atributo relacional es que también puede pensarse en su

\footnotetext{
${ }^{18}$ Idem.

${ }^{19}$ Poulantzas, op. cit., 30.

${ }^{20}$ Poulantzas, op cit., 154.
} 
autonomía relativa y la importancia de su intervención en el procesamiento cotidiano de las contradicciones de clase y el equilibrio requerido para mantener el orden social.

A partir del reconocimiento de estas contradicciones es que también se evita el esquematismo de una concepción monolítica e infalible del Estado como mero instrumento al servicio de una clase social, posibilitando sopesar la singularidad de las situaciones históricas y los episodios que pueden contribuir a minar, en menor o mayor medida, su autoridad y los intereses de clase que garantiza. De hecho, el Estado debe enfrentarse a las transformaciones que puedan desencadenarse en las relaciones de producción y las luchas de clase que presenten estos procesos para afrontar, en cada contexto, la organización de las contradicciones emergentes. Son, finalmente, los intersticios que señala García Linera ${ }^{21}$, y que permiten dimensionar en su justa medida el accionar y las contradicciones sociales que licúa el Estado en el colectivo nacional que gobierna y que afanosamente busca unificar mediante la construcción permanente de una identidad común. Huellas intersticiales que necesariamente debe dejar en el ejercicio de sus actos si pretende aparentar ser el garante de los intereses de toda la comunidad y no solo de un sector de ella.

\section{Las grietas concedidas}

El Estado definido como relación en el que se materializan y condensan las fuerzas en pugna permite entender su dominación política como un proceso continuo y concreto, de equilibrio y organización de las contradicciones y conflictos de clase. Esta noción "procesual" de la dominación, que supone la continuidad de una práctica estatal que lo avale, se contrapone a la noción de Estado como cosa, como elemento, que deba ser tomado desde afuera. Pero paralelamente también supone la apertura de condiciones para que las clases dominadas puedan conquistar mayores espacios de poder dentro del Estado y de cada uno de sus aparatos.

De acuerdo a García Linera, este es el gran aporte reflexivo de Poulantzas vinculado a la dominación política del Estado: el continuo devenir de las relaciones de fuerza que condensa, la búsqueda del equilibrio en la relación que mantienen las clases dominantes con las clases dominadas, lo hacen blanco de nuevos espacios, de "huecos", que son los que abren las posibilidades de resistencia y de emancipación de éstas últimas. ${ }^{22}$ En efecto, en el proceso continuo de renovación de esta dominación, del mantenimiento hegemónico de los intereses de la burguesía y del consenso que debe lograr con otras clases, se encuentran las oportunidades de acabar con este orden, puesto que este devenir toma forma en espacios estatales concretos donde logran objetivarse los flujos permanentes de las luchas sociales y las relaciones de fuerza resultantes. Estas relaciones sociales se materializan, logrando institucionalizarse muchas de ellas y dejando registros que pueden estabilizar cambios (culturales, simbólicos y económicos) que horaden el dominio político del Estado capitalista.

\footnotetext{
${ }^{21}$ Ibid., 9.

${ }^{22}$ Ibid., 8-9.
} 
En tales términos, representan el estado de las relaciones de dominación existentes y el consenso que, en mayor o menor medida, puede comparecer la autoridad estatal. En palabras de García Linera esta dominación se manifiesta en las mentes de las personas que conforman la comunidad sobre la que el Estado gobierna, incidiendo en su percepción del mundo y en las prácticas cotidianas de cada una de ellas. Son estas estructuras mentales y simbólicas de las personas las que permiten la interpretación del mundo en el que viven y la "naturalización" de la organización social jerarquizada, representada y reproducida por el Estado. Aquí reside la legitimidad de su dominación, que encierra en la idea de comunidad organizada, la neutralización de los proyectos emancipatorios de las clases dominadas.

No obstante, esta idea tiene que reproducirse en la articulación cotidiana con las clases sociales que no son parte de las clases dominantes, y aquí es también cuando pueden abrirse las grietas emancipadoras que destaca García Linera. En la necesidad permanente de revalidar los procesos que hacen a la búsqueda del equilibrio y la organización de las contradicciones propias del dominio político es cuando aparecen estas oportunidades. Si la dominación tiene la necesidad permanente de legitimarse es porque reconoce el equilibrio contingente de las relaciones de fuerza entre clases que se condensan y materializan en el Estado. Sobre este vacío, entonces, es que pueden pensarse las resistencias y los cuestionamientos al orden social jerarquizado representado por la comunidad nacional organizada. Solo concibiendo al Estado como condensación material de relaciones de fuerza específicas y variables es que también puede ser pensada una vía democrática de acceso al socialismo que no apele a la "toma" irruptiva del poder.

\section{La vía democrática al socialismo}

Desde su experiencia como vicepresidente en el gobierno del Estado plurinacional boliviano, García Linera reivindica la propuesta poulantziana de acceso democrático al socialismo. En realidad, desde la óptica del Estado entendido como relación de fuerzas condensadas, donde se encuentran intereses de distintas clases sociales, y del reconocimiento de la diversidad cultural en el propio Estado boliviano, es que la concibe como la alternativa más viable de acceso al socialismo. Observa en el Estado otro lugar de disputa en el que se trasladan las relaciones de fuerza que atraviesan al conjunto de la sociedad y, por ende, también a éste. De manera que el socialismo como hecho estructural transformador de las relaciones de fuerza también sacudiría la dominación política del Estado capitalista "que por otra parte no es más que la institucionalización material e ideal, económica y cultural, de esa correlación de fuerzas sociales"23.

En el marco de este proceso, entonces, tendría efectos considerables la erosión del monopolio de los valores universales y cohesionadores propugnados por el Estado y el desarme de su dominación política bajo la hegemonía de las fracciones de clase dominantes. Pero es un proceso que García Linera - retomando de nuevo a Poulantzas- lo concibe a largo plazo y contrapuesto a las tomas del poder por asalto que sostuvieron el

${ }^{23}$ Ibid., 13.

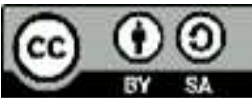


ideario de los movimientos revolucionarios del siglo pasado. Este proceso es el que en definitiva sostendría las experiencias políticas que se sucedieron en algunos países de Latinoamérica en los últimos años, y que en el caso de Venezuela, por intermedio del ya extinto ex presidente Hugo Chávez, tuvo una denominación clara: "Socialismo del siglo XXI". En este sentido, la argumentación teórica que ensaya García Linera pretende desmarcarse decididamente de las nociones clásicas del marxismo que situaban al Estado capitalista como un acabado instrumento de dominación burguesa impermeable a la transformación social. Por el contrario, el "Socialismo del siglo XXI" parece hacer posible esta transformación aun en sistemas políticos que históricamente fueron tildados de demoliberales. En efecto, en las visiones clásicas del marxismo, el Estado debía ser tomado en un momento preciso, al calor de la agudización de las contradicciones de clase retraducidas en procesos revolucionarios concretos e identificables, para acabar con el régimen burgués imperante (incluyendo las formas democráticas de la dominación burguesa). En el nuevo ideario, en cambio, las transformaciones son pensadas a largo plazo y sobre la progresión continua de actos que apuntan a cambiar de manera radicalizada la correlación de fuerzas de las clases dominadas o subalternas. Estos actos de cambio estructural se materializan al interior de los distintos espacios estatales expresándose, justamente, en nuevas y distintas formas de participación democrática y asociación colectiva que predisponen nuevas formas de organización de la vida cotidiana. Constituyen, en definitiva, la reserva democrática del nuevo socialismo propugnado por Poulantzas: un socialismo que, en oposición al modelo soviético, debe ser democrático o no $\operatorname{ser}^{24}$.

Cabe señalar que este ideario socialista, que privilegia las instancias de democratización directa de base, le sirvió también a Poulantzas para terminar de rechazar las concepciones instrumentalistas del Estado y las secuelas prácticas que tuvo en la Unión Soviética y en otros "socialismos reales". De acuerdo al marxista greco-francés, estas definiciones incidieron en la burocratización y en el estatismo soviético al ubicar al Estado capitalista como un ente externo y ajeno a las contradicciones de clase. Concebido en tanto instrumento de la Burguesía, como cosa que se toma y se utiliza, no fue pensado como ámbito en el que tuvieran lugar contradicciones internas que expresaran la lucha de clases y que, en consecuencia, pudiera ser transformado. Y, por ende, tampoco se puso en marcha un proceso de transición al socialismo en ese mismo Estado sobre prácticas concretas que pudieran desarrollarse en su interior.

\section{Recapitulando}

Hasta aquí, siguiendo la exposición inicial, se ha querido de manera progresiva instalar argumentos que desde la experiencia latinoamericana permitieran acabar con cualquier noción instrumentalista del Estado. Primero se ha intentado desmarcar a Marx de esta concepción vinculando el protagonismo que tuvieron los Estados en la constitución de las naciones latinoamericanas en paralelo a la consolidación de las condiciones de producción

\footnotetext{
${ }^{24}$ Poulantzas, op. cit., 326.
} 
capitalistas, de las que fueron activos partícipes. En tal sentido, Marx marca registro de esto al describir las acciones estatales que concurrieron al conjunto de factores que viabilizaron la acumulación originaria del capital en la Europa occidental. Pero también marca su ausencia en otras latitudes, dejando constancia que el capital no existe como cosa en sí sino en tanto resultado de procesos históricos concretos que incluye agentes e intereses también concretos.

En esta dinámica es que puede pensarse también en la participación que tuvo el Estado en Latinoamérica en la modelación de las identidades, las tradiciones culturales y los límites espaciales de cada nación. La formación de una comunidad, de un colectivo nacional en un espacio social y territorialmente organizado en el que se pudieran sostener relaciones de producción capitalistas, que todavía estaban ausentes o no se habían afianzado suficientemente, conduce al descarte temprano de cualquier noción de Estado que le confiriera un rol puramente instrumental. En efecto, las tareas de organización nacional suponen otros desafíos y otras relaciones con el conjunto del colectivo social sobre el que se proyecta la dominación política. Aun cuando sea bajo la hegemonía de los intereses de una clase en particular, la pertenencia comunitaria y los recursos compartidos asociados a ella deben sostenerse como impulso integrador de las distintas clases sociales. En este marco es que cobra vitalidad la definición de Estado como condensación material de relaciones de fuerza entre distintas clases sociales que, concebida por Poulantzas, también es utilizada por García Linera al momento de pensar las posibilidades que tienen las clases dominadas de acabar con este tipo de dominación política.

De acuerdo a esta consideración, el Estado-nación en el capitalismo aparenta representar a toda la sociedad y en alguna medida lo hace al promover la ejecución de determinadas políticas públicas (después de todo, la cohesión social es un estado que debe procurarse con acciones concretas), aunque en definitiva estén subordinadas a otras determinaciones principales encaminadas a respaldar los intereses de una clase: la burguesía. Logra bajo su dominación hegemónica licuar muchas de las contradicciones de clase que habitualmente afloran y se manifiestan como conflictos sociales (otras directamente se reprimen). En estas circunstancias, las relaciones de fuerza se nivelan, y el poder del Estado adquiere cierta independencia momentánea respecto a las clases dominantes. Aquí es cuando tiende a ser más probable que las políticas estatales propendan a una mayor porosidad ofreciendo intersticios sobre los que se logre obrar, en mayor o menor medida, en función de las relaciones de fuerza de cada momento histórico. Aquí también es cuando logran adquirir mayor protagonismo y visibilidad las actividades cotidianas que hacen al Estado, es decir, las actividades que lo vivifican y lo hacen concreto $^{25}$, cuya lógica puede perfectamente expandirse en el terreno de las políticas públicas y ser aplicada en la cotidiana realidad sobre la que operan (y son operadas). En efecto, existen los "actos" y los "trabajos" de los agentes individuales o colectivos, procesos políticos que definen las relaciones concretas del Estado "vivo" que pueden ejercer cierta influencia desde las políticas a la política: "el Estado no existe jamás en sí,

\footnotetext{
${ }^{25}$ Jean Padioleau, El Estado en concreto, México, Fondo de cultura económica, 1989.
} 
sino siempre bajo el ángulo de relaciones con otros actores", pudiendo condensar materialmente estas relaciones en una "unidad contradictoria de clases y fracciones políticamente dominantes bajo la égida de la fracción hegemónica"26. En este contexto, el accionar del Estado y las políticas públicas que formula se ubican en una posición de autonomía relativa y de interacción con otros sectores de la sociedad que en la organización de las contradicciones de clase, ante cambios en las relaciones de fuerza, pueden habilitar procesos tendientes a cuestionar su dominación política y, eventualmente, el desarrollo de nuevas formas de participación democrática.

Estas son las vigas de apoyo sobre las que tanto Poulantzas como García Linera edifican la potencialidad de un socialismo democrático. Socialismo que, por otro lado, no es ajeno a un contexto histórico marcado por la decadencia y posterior disolución de los llamados "socialismos reales", y luego por las consecuencias que produjo la aplicación de políticas neoliberales en no pocos gobiernos latinoamericanos durante la década de 1990. Este también es el marco en el que se manifestaron los esfuerzos de buena parte de la filosofía política contemporánea para dar respuesta a lo que Althusser prontamente denominó "crisis del marxismo" 27 y que Poulantzas asumió en la elaboración de sus escritos. (Tarea que posteriormente ejercerían otros autores, como Bobbio ${ }^{28}$ y Negri ${ }^{29}$, contribuyendo a dar cuenta, a partir de la revisión de no pocos tópicos marxistas, del ocaso de un postulado dialéctico que en sus versiones más teleológicas presagiaba la voluntad revolucionaria de un sujeto histórico que pondría fin a la explotación del hombre por el hombre).

Esta es la trama contextual en la que es reivindicada la figura de Poulantzas en los decires de García Linera, en la necesidad de repuntar la emancipación social en las democracias de occidente, y particularmente en las latinoamericanas, luego de los sucesivos gobiernos neoliberales que asolaron la región. Este nuevo rumbo del discurso emancipatorio se aleja así de las tradiciones del campo socialista que identificaban en el Estado un instrumento de dominación que había que abolir para pensar, en cambio, en los recursos que puede ofrecer, desde su autonomía relativa, en un régimen democrático. Sin embargo, son bases de apoyo que en simultáneo al énfasis con que prohíjan los cambios en las relaciones de fuerza que permitirían acceder al socialismo, no contemplan demasiado los mecanismos de resistencia de la clase dominante, es decir, las acciones que la burguesía podría emprender para contrarrestar esos cambios. Tampoco reparan en el monopolio de la coerción física legal que detenta el Estado, y el efectivo uso que puede hacer de la violencia para detener estos procesos si de lo que se trata es de sostener, en última instancia, los intereses de una clase en particular.

\footnotetext{
${ }^{26}$ Nicos Poulantzas, Poder político y clases sociales en el estado capitalista, México, Siglo Veintiuno Editores, 1969, 308.

${ }^{27}$ Louis Althusser, La soledad de Maquiavelo, Argentina, Ediciones Akal, 2015.

${ }^{28}$ Norberto Bobbio, ¿Qué socialismo?, Barcelona, Plaza y Janes, 1986.

${ }^{29}$ Antonio Negri, Marx más allá de Marx: cuaderno de trabajo sobre los Grundisse, Madrid, Ediciones Akal, 2001.
} 
Poulantzas distingue distintas áreas del Estado en las que las relaciones de fuerza comportarían una dinámica propia; señala para ello el caso particular de algunos organismos de seguridad del Estado y, en general, de todo su aparato represivo. ${ }^{30}$ No obstante, más allá de que con esta distinción asoma una preocupación analítica por este problema, no avanza más allá de su enunciación, resaltando solo la necesidad de que un amplio movimiento popular respalde a este nuevo socialismo. ${ }^{31}$ García Linera también parece comprender que, ante un avance de las clases subalternas y un cambio en las relaciones de fuerza, la progresiva corrosión de la dominación política del Estado capitalista podría verse obstaculizada por la resistencia de la burguesía al ver amenazados sus privilegios de clase y su hegemonía en el aparato estatal. Sin embargo, el peligro de estas reacciones para los movimientos políticos que pretenden instaurar el socialismo no es abordado por el vicepresidente de Bolivia, y mucho menos es sopesado el poder de fuego que puede ser utilizado por la burguesía.

Llegados a este punto, conviene identificar en esta nueva concepción socialista no solo una crítica al Estado-cosa o Estado-instrumento sino también una crítica a las armas, a la violencia que debía ser usada para tomar ese Estado y hacerse del poder. La derrota de muchos movimientos revolucionarios del siglo XX y la desaparición de los "socialismos reales" supusieron también el surgimiento de reflexiones éticas y cuestionamientos incisivos respecto a la violencia desatada en nombre de las transformaciones sociales y la revolución como legítima bandera de la igualdad entre los hombres. La revisión general de la obra de Marx y del marxismo, que a partir de la crítica política, histórica y filosófica expresó el reconocimiento de los límites teóricos y prácticos de ciertos postulados "clásicos", tuvo entre sus consecuencias el desplazamiento teórico y metodológico de los asaltos violentos como medio de conquista del poder político (así, en Poulantzas y García Linera este desplazamiento desemboca en un mayor despliegue de las tareas de construcción de hegemonía de las clases subalternas acentuando el rol que ocupan la cultura y las ideas políticas como productoras de cambios sociales). Las sospechas sobre el Estado-cosa, en tanto concepción adscripta a una tradición marxista profundamente intervenida por el estalinismo soviético -y, por tanto, sujeta a revisión-, conspiraron para que se relegara el alcance de sus funciones coercitivas: el afán por querer desprenderse de cualquier definición instrumentalista del Estado descuidó sus propiedades como fuerza de choque, como garrote represivo, de las clases dominantes y garante de las relaciones de producción capitalistas (algo que Poulantzas alcanza a prever hacia el final de Estado, poder y socialismo). Estas funciones, que también son descriptas con elocuencia por Marx, en tanto organizan y direccionan la violencia institucionalizada, perdieron su protagonismo entre las condiciones que debían ser enfrentadas para la toma del poder, y supusieron también relegar como aspecto de relevancia el uso de la violencia física como medio y sostén de las trasformaciones sociales proyectadas.

\footnotetext{
${ }^{30}$ Nicos Poulantzas, Estado, poder y socialismo, México, Siglo Veintiuno Editores, 2005, 87-95 y 166-168.

${ }^{31}$ Poulantzas, op. cit., 324.
} 
Empero esto no deja de abrir interrogantes en torno a la factibilidad de un régimen que para poder realizarse debe ser democrático, pero también socialista. Son cuestiones que no dejan de llamar la atención en los planteos de García Linera, pues en resumidas cuentas el "Socialismo del siglo XXI" al que podría adscribir el vicepresidente de Bolivia encuentra una referencia inmediata en el gobierno de Salvador Allende y la llamada "vía chilena al socialismo"; experiencia democrática de la Unidad Popular que culminó a sangre y fuego bajo el gobierno dictatorial de Pinochet y que a la postre significó la apertura de las políticas neoliberales en la región. Esta experiencia demostró no solo que los cambios sociales propuestos por el gobierno de Allende necesitaban de un Estado férreo que los garantice, sino que la libre circulación del capital y los mercados suponen también la imposición represiva de reglas de juego que los institucionalicen. Sin embargo, en un contexto latinoamericano como el que hoy se atraviesa, donde han surgido gobiernos que reivindican procesos políticos de emancipación y transformación tendientes a una mayor conquista de derechos sociales, esto parece ser olvidado; la revisión lo ha dejado de lado. Esto invita a pensar no solo en las funcionalidades de un socialismo concebido en estos términos, es decir, si puede especularse con la formación de un socialismo democrático -en vista de la experiencia chilena- sino, además, si los llamados socialismo del siglo XXI pueden ser considerados como tales en virtud de los intereses creados que atacan (y de la peligrosidad para el establishment que esto pueda significar); esto es, si apuntan a cambiar verdaderamente las estructuras de poder y las relaciones de desigualdad de clase imperantes en el capitalismo. ${ }^{32}$ Aquí se trastocaría la pregunta que da título a este artículo. En este caso ya no se trataría de responder si el Estado capitalista es un agente procesador de cambios o un mero instrumento de dominación -los argumentos presentados a lo largo del artículo dan cuenta de la capacidad de hacerlos posibles- sino si esos cambios, bajo los cuales asomaría un socialismo democrático, no comportan en realidad un nuevo velo bajo el que se reproduce la dominación de clase. Todo lo cual, no supondría meramente un cuestionamiento fáctico a los socialismos democráticos o socialismos del siglo XXI, sino más bien un llamado de atención respecto a los límites analíticos de la llamada autonomía relativa del Estado y el peligro que pueden encerrar sus derivaciones prácticas.

\section{Bibliografía}

Fuentes impresas

- $\quad$ Louis Althusser, La soledad de Maquiavelo, Argentina, Ediciones Akal, 2015.

- Norberto Bobbio, ¿Qué socialismo?, Barcelona, Plaza y Janes, 1986.

- David Harvey, Espacios del capital: Hacia una geografia crítica, Madrid, Ediciones Akal S.A., 2011.

\footnotetext{
${ }^{32}$ También se podría incluir en esta reflexión la situación política de muchos partidos socialistas de raigambre más "clásica" (marxistas-leninistas, maoístas, trotskistas, etc.), que en el mejor de los casos logran asomar bajo un horizonte exclusivamente parlamentarista sin que definan estrategias concretas de poder.
} 
- Carlos Marx, El capital: Crítica de la economía política, México, Fondo de cultura económica, 1995.

- Antonio Negri, Marx más allá de Marx: cuaderno de trabajo sobre los Grundisse, Madrid, Ediciones Akal, 2001.

- Oscar Oszlak, Andrés Fontana y Leandro Gutiérrez, La formación del Estado argentino, Buenos Aires, Editorial de Belgrano, 2004.

- Jean Padioleau, El Estado en concreto, México, Fondo de cultura económica, 1989.

- Nicos Poulantzas, Poder político y clases sociales en el estado capitalista, México, Siglo Veintiuno Editores, 1969.

- Nicos Poulantzas, Estado, poder y socialismo, México, Siglo Veintiuno Editores, 2005.

- René Zavaleta Mercado, Clases sociales y conocimiento, La Paz, Editorial Los Amigos del Libro, 1988.

Fuentes electrónicas o digitalizadas

- José Aricó, “Marx y América Latina”, revista Nueva Sociedad NRO. 66 mayo-junio 1983. Disponible en http://nuso.org/media/articles/downloads/1061 1.pdf (obtenido el 5 de abril de 2016).

- Álvaro García Linera, "Estado, democracia y socialismo", Universidad de la Sorbona de París, Coloquio Internacional dedicado a la obra de Nicos Poulantzas: un marxismo para el siglo XXI, 2015. Disponible en http://www.rebelion.org/noticia.php?id=195607 (obtenido el 5 de abril de 2016). 